\title{
Revisiting the Outsiders: Innovative Recruitment of a Marijuana User Network via Web-Based Respondent Driven Sampling
}

\author{
Seth S. Crawford \\ Department of Sociology, School of Public Policy, Oregon State University, Corvallis, USA \\ Email: seth.crawford@oregonstate.edu
}

Received November 14, 2013; revised December 21, 2013; accepted January 7, 2014

Copyright (C) 2014 Seth S. Crawford. This is an open access article distributed under the Creative Commons Attribution License, which permits unrestricted use, distribution, and reproduction in any medium, provided the original work is properly cited. In accordance of the Creative Commons Attribution License all Copyrights (C) 2014 are reserved for SCIRP and the owner of the intellectual property Seth S. Crawford. All Copyright @ 2014 are guarded by law and by SCIRP as a guardian.

\section{ABSTRACT}

This study uses an innovative, network-based recruitment strategy (non-monetary, web-based respondent driven sampling) to gather a sample of il/legal marijuana users. Network-driven effects amongst marijuana users are examined to test the explanatory validity of several theories of social deviance. The study finds that respondent driven sampling techniques lack effectiveness without primary monetary incentives, even when meaningful secondary incentives are utilized. Additionally, the study suggests that marijuana user networks exhibit strong homophilic attachment tendencies.

\section{KEYWORDS}

\section{Marijuana; Respondent Driven Sampling; Social Network Analysis Methods}

\section{Introduction}

Aside from using marijuana, are there any substantial differences between regular marijuana users and the general population? Does the composition of marijuana users' friendship networks affect their use of the drug? What do these friendship networks suggest about relations with non-users? Are there any differences between illegal marijuana users and licensed medical marijuana users? Finally, can individual-level factors explain the varying rates of medical marijuana patient participation between geographic areas? This study addresses these questions using a survey of marijuana users in Oregon-a location ripe for investigation along these lines. Oregon has one of the highest rates of marijuana use in the US, with the most recent estimate indicating that $14.09 \%$ of individuals over 12 years old have used marijuana in the last year (compared to the US average of 10.2\%) [1]. Oregon is also home to one of the oldest medical marijuana programs in the US, established in 1998, just two years after the first was created in California, and publishes countylevel counts of medical users dating back to 2005. Oregon consistently ranks in the top ten states for plants seized by the Drug Enforcement Administration, with estimates of production valued at $\$ 473$ million in 2005, making it the state's largest agricultural commodity [2]. Even with a firmly entrenched federal prohibition on marijuana, there is a strong possibility that Oregon's quasi-legalization (through its medical program) makes the likelihood of more candid responses from respondents possible.

The sample for this study is gathered using a Respondent-Driven Sample (RDS) procedure [3]. After assembling the sample, respondents answered questions relating to their social characteristics, health concerns/problems, political ideology, drug abuse potential, and their community's acceptance of marijuana use. In this study, I provide an overview of pertinent literature and theoretical expectations, outline the methods used to assemble the sample and analyze collected data, discuss the findings, and describe possible future research directions.

\section{Literature Review}

\subsection{Marijuana Users}

Marijuana is the most widely used illicit drug in the 
United States, with 16.7 million US residents estimated to have used the drug in the last 30 days and 4 million using it 300 days per year or more [1]. Males are nearly twice as likely to report using marijuana regularly as females, and individuals between the ages of 18 and 25 are the prime demographic group of consumers [1]. Despite the near-monopoly on use by young people, older adults are increasing their use of marijuana in the US as the baby-boomer generation ages [4]. With the exception of Asian Americans, non-whites are more likely to use marijuana than whites [1]. College graduates are less likely to be current users than those with lower educational attainment, though more likely to have tried marijuana [1]. Additionally, individuals who are employed full time have lower rates of use than those who are either unemployed or working part time [1]. Finally, rates of use increase monotonically with city/area of residence size [1].

\subsection{Theoretical Overview}

Becker originally detailed the cultural assimilation process that must occur for individuals to become initiates of a marijuana user community [5,6]. Potential community members must first learn how to properly consume marijuana, learn to perceive its effects, and, finally, learn to enjoy the effects. Once a user moves to this third stage, they have the potential to continue use-though this possibility is mediated by a number of social control mechanisms. These mechanisms include: "(a) control through limiting of supply and access to the drug; (b) control through the necessity of keeping nonusers from discovering that one is a user; (c) control through definition of the act as immoral" (61). Due to its illegality, an individual must have connections to elements of society where marijuana is readily available. At first, this means simply using with others who have access; however, as a person progresses into a "more regular and systematized mode of use, he can do it only by finding a more stable source of supply than more-orless chance encounters with other users, and this means establishing connections with persons who make a business of dealing in narcotics" [6]. The veil of secrecy surrounding one's marijuana use is important to ward off "repudiation by people whose respect and acceptance he requires both practically and emotionally" [6]. To combat the dominant meme that marijuana users are immoral (unable to be responsible for their own welfare or rationally mediate their behavior, particularly relating to impulse control around use), frequent users must acquire a "more emancipated view of the moral standards implicit in the usual characterization of the drug user" [6]. This is generally accomplished by acquiring "a series of rationalizations and justification with which he may answer objections to occasional use", such as comparing the ac- tivity to more harmful, socially accepted behaviors (alcohol and nicotine use) or generating positive narratives about the drug's effects [6].

The core of labeling theory revolves around the differentiation between primary and secondary deviance; primary deviance is an initial deviant act by an individual (whether intentional or unintentional) that is observed by someone else with the power to castigate or rebuke [6]. Once this primary act is observed, the deviant label can be applied to the offending individual; the likelihood of the label becoming affixed to an individual is influenced by their position within society (more powerful people have less chance of receiving the formal label). Secondary deviance refers to any action that results from someone being labeled "deviant"; once labeled, individuals may have a propensity towards further deviant behavior or will have their opportunities limited to participating in deviant groups. Under this framework, the application of rules, mores, and norms are not viewed as occurring in a vacuum; “moral entrepreneurs” actively pursue agendas to outlaw specific activities that they deem inappropriate or deleterious to society [6]. Once enacted, the laws are upheld by "rule enforcers" (usually law enforcement officers), who face the dual problem of demonstrating their proficiency at stomping out acts of deviance and pointing to the deviant acts as a continuing scourge (which is particularly apparent in the marijuana realm).

Sutherland's differential association theory (DA) posits a bifurcation in society between criminal and noncriminal activities, and attributes the engagement of individuals in criminal behavior to socialization processes occurring in close relationships [7]. DA began with nine propositions explaining the process of learning and committing criminal/deviant behavior:

1) Criminal behavior is learned; 2) criminal behavior is learned in interaction with other persons in a process of communication; 3) the principal part of the learning of criminal behavior occurs within intimate personal groups; 4) when criminal behavior is learned, the learning includes techniques of committing the crime, which are sometimes very complicated, sometimes simple and the specific direction of motives, drives, rationalizations, and attitudes; 5) the specific direction of motives and drives is learned from definitions of legal codes as favorable or unfavorable; 6) a person becomes delinquent because of an excess of definitions favorable to violation of law over definitions unfavorable to violation of the law; 7) differential associations may vary in frequency, duration, priority, and intensity; 8) the process of learning criminal behavior by association with criminal and anti-criminal patterns involves all of the mechanisms that are involved in any other learning; 9) while criminal behavior is an expression of general needs and values, it is not explained by those needs and values, since non-criminal 
behavior is an expression of those same needs and values [7].

Once deviant learning has commenced through differential associations, the likelihood of an individual engaging in deviant activity becomes dependent upon their internalization of pro-deviant rationalizations, though there are a number of possible causal routes proposed. Tittle et al. characterize these causal routes as:

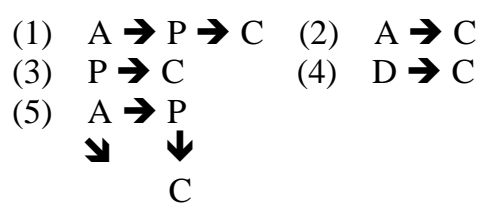

where: $\mathrm{A}$ = individual association with definitions favorable to law violation; $\mathrm{P}=$ criminal perspectives (attitudes rationalizations, etc.); $\mathrm{D}=$ definitions in the environment are favorable to law violation; $\mathrm{C}=$ criminal behavior [8].

The application of DA to marijuana use has yielded mixed results, due in large part to the populations selected for study. The majority of marijuana use studies focus on adolescents and attempt to delineate the causal mechanisms driving initial use, though some also attempt to explain continued use (these studies are explicated in the "empirical studies" section); however, studies of adults who continue to use are relatively rare. This is due, in large part, to the history of funding by federal agencies (National Institute on Drug Abuse, National Institutes of Health, and Substance Abuse and Mental Health Services in particular), which tend to direct research dollars towards adolescent drug use prevention strategies and studies, and, if adult research is funded, is focused on substance abusers (with anyone using marijuana receiving that label).

Social learning theory offers a reformulation of DA theory [9-11]; Akers et al. propose the following pattern of social processes leading to (or away from) deviant behavior:

The primary learning mechanism in social behavior is operant (instrumental) conditioning in which behavior is shaped by stimuli which follow, or are consequences of the behavior. Social behavior is acquired both through direct conditioning and through imitation or modeling of others' behavior. Behavior is strengthened through reward (positive reinforcement) and avoidance of punishment (negative reinforcement) or weakened by adversive stimuli (positive punishment) and loss of reward (negative punishment). Whether deviant or conforming behavior is acquired and persists depends on past and present rewards or punishments for the behavior and the rewards and punishments attached to alternative behavior-differential reinforcement. In addition, people learn in interaction with significant groups in their lives evaluative definitions (norms, attitudes, orientations) of the behavior as good or bad. These definitions are themselves verbal and cognitive behavior which can be directly reinforced and also act as cue (discriminative) stimuli for other behavior. The more individuals define the behavior as good (positive definition) or at least justified (neutralizing definition) rather than as undesirable (negative definition), the more likely they are to engage in it [12].

Reinforcers of behavior are most often important groups-peer-friendship groups, schools, parents, and churches-but also include nonsocial aspects, such as physical reactions to ingested of drugs. In simple terms, a person associates with peers who engage in deviant behavior, learns to define the behavior favorably, then engages in the behavior. Maintaining deviant behavior is often only possible when an individual, on balance, receives more confirmatory messages than approbation regarding the specific act. In the case of drug use, Akers et al. specifically state that:

After the initial use, imitation becomes less important while the effects of definitions should continue (themselves affected by the experience of use). It is at this point in the process that the actual consequences (social and nonsocial reinforcers and punishers) of the specific behavior come into play to determine the probability that use will be continued and at what level. These consequences include the actual effects of the substance at first and subsequent use (the perception of which may, of course, be modified by what effects the person has previously learned to expect) and the actual reactions of others present at the time or who find out about it later, as well as the anticipated reactions of others not present or knowing about the use [12].

The effect of a particular drug on a user-the subjective experience-is argued to be a powerful determinant of continued use, a point well established in Becker's and Goode's respective studies of marijuana users $[6,13]$. Perceived reactions from affiliates also take on a more powerful determinative force in continued use.

In opposition to both DA and social learning theories, Hirschi's social control theory proposes that deviant activity is not a response to learned behavior; rather, it emerges from a lack of social bonds (attachment, commitment, involvement, and belief) [14]. This approach implicitly assumes that deviance exists in societies and seeks to identify the causes (controls) at work in the absence of deviance. In Hirschi's framework, attachment signifies emotional connections with others, which leads to actions that conform to the expectations of those we care about. Commitment refers to the level of integration an individual feels towards conventional social institutions, roles, and processes, such as education, family, and occupation. Involvement refers to the rational calculation of time available to each person; if someone is working a 
full time job, raising a family, participating in community activities, and spending time with friends, they are much less likely to engage in deviant behavior simply due to time requirements of leading a "straight" life. Belief describes the intensity of acceptance an individual has towards the dominant values, rules, and norms of their society; the more someone accepts the official rules as right and proper, the less likely they are to commit acts in antagonism towards the status quo. Social control theory operates under the assumption that individuals understand the consequences of their behavior and will consistently act in a rational way to preserve their feelings, position amongst close associates, and level of integration in society-which is a significant point of contention for some [15].

Studies of marijuana users corroborate the assembled theoretical model offered by Becker, finding that individual attitudes towards the harmfulness of the drug are consistent predictors of both initial and continuing use [16], and that peer networks provide a key influence in the development and maintenance of these requisite attitudes [13,17]. The logical extension of this idea is that frequency of use is directly related to the proportion of friends who use and the perceived acceptance of marijuana use among a person's peer group; I expect that individual marijuana use will increase with the number of friends who use, as well as self-reported peer-group acceptance of marijuana use.

$\mathrm{H}_{1}$ : Individual marijuana use will increase with the number of friends who use marijuana

$\mathrm{H}_{2}$ : Individual marijuana use will increase with peergroup acceptance of marijuana use

Mauss situates marijuana experimentation within the context of college preparation, arguing that many university-bound high school students begin use before matriculating to assist in the cultural assimilation process [18]. Conversely, Brown finds that college students cease marijuana use following graduation, citing social pressures of work, family, and social integration as key causal factors [19]. Yamaguchi and Kandel use cross-sectional event history analysis to demonstrate that marijuana use is negatively related to marriage and becoming a parent, yet positively related with separation/divorce [20]. Since this study's sample will consist entirely of marijuana users, I expect that the average level of education will be higher than the general population, and that more individuals will be single (or divorced) and childless than the general population.

$\mathrm{H}_{3}$ : Marijuana users are more educated than the general population

$\mathrm{H}_{4}$ : Marijuana users are more likely to be single than the general population

$\mathrm{H}_{5}$ : Marijuana users are more likely to be childless than the general population
Do licensed medical marijuana users differ from their illegal counterparts in their rationalizations for using the drug? The universe of possible reactions to marijuana are multifaceted and, often, mutually contradictory; Goode’s qualitative study of users (all illegal) illustrates this phenomenon well [13]. Reinarman et al. provide the lone scholarly attempt at identifying characteristics of medical marijuana users [21]. Using a sample of 1746 patients from nine separate medical marijuana clinics in California, the authors find that Blacks and Native Americans use at higher rates than other ethnic groups, while Latinos and Asians have lower rates of use (Whites are near the average for all groups). Use is heaviest in the 25 - 44 year age range, and males made up $73 \%$ of the sample. Chronic pain suppression and improved sleep were the most commonly cited uses/benefits of marijuana reported by subjects (82.6\% and $70.7 \%$, respectively). Other conditions/uses of medical marijuana included relaxation (55\%), muscle spasms (41\%), headaches (41\%), anxiety (38\%), nausea (28\%), and depression (26\%). Studies of non-medical use suggest two dominant views by users: 1 ) the drug is perceived to stimulate creative thinking, particularly among artists, musicians, and writers, and 2) users consume it to relax and experience euphoria [6] [13]. Weil et al., in the first controlled study of marijuana use, found that self-reported feelings of well-being were improved with consumption of the drug, and that the intensity of these feelings was dose-dependent [22]. Zablocki et al. also document the feelings of euphoria that accompany use, though they find that these feelings are more commonly reported by individuals who score low on scales of introspectiveness [23]. Further, a strong experiential dichotomy is present between introspectives/non-introspectives, where the former associate their experience with marijuana "in self-oriented cognitive and emotional terms", and the latter focus on "distortions of normal sensorimotor functioning and disruptions or modifications of normal everyday activities" [23]. For the highly introspective individual, the experience seems to:

Stimulate global self-evaluations and sharpen the contrast between the ideal and the perceived self. Rather than being distracted from personal problems of unusual sights, sounds, or tastes, such persons may experience marijuana as a confrontational drug, which focuses attention on the very aspects of self that are currently most troublesome [23].

While there is pointed evidence indicating that the drug affects individuals in varying manners, the subjective experiences described by users also points to a methodological problem unaddressed by previous research: different varieties of marijuana ("strains") tend to elicit different results. Hillig and Mahlberg's review and analysis of 157 different cannabis accessions lends credibili- 
ty to the anecdotal evidence reported by users; genomically, drug cultivars of cannabis are limited to two subspecies of cannabis indica (narrow and broad-leaf varieties), with narrow leaf plants generally producing soaring mental euphoria in users and broad-leaf plants inducing a more lethargic, body-numbing effect [24]. The wide variation in effect is attributed to different ratios of two key cannabinoids in these plants-THC and CBD—-with low amounts of CBD in narrow leaf varieties and high amounts in broad-leaf plants.

Plant-induced variations in experience aside, current evidence suggests that medical users of the drug will focus on symptom alleviation in an attempt to rationalize their use; non-medical users should report using for either creative stimulation/personal insight or simply to numb themselves from reality (i.e. getting “stoned”).

$\mathrm{H}_{6}$ : Medical users will use primarily to alleviate acute physical symptoms

$\mathrm{H}_{7}$ : Illegal users will use to stimulate creativity, generate personal insight, or to numb themselves from reality

In the following sections, I describe the methods used to assemble the sample for this study, provide a description of the results, and discuss the implications of my findings.

\section{Methods}

Accessing hidden populations-a status marijuana users, producers, and sellers are relegated to in the United States-poses two unique challenges to investigators; as Heckathorn notes:

First, no sampling frame exists, so the size and boundaries of the population are unknown; and second, there exist strong privacy concerns, because membership involves stigmatized or illegal behavior, leading individuals to refuse to cooperate, or give unreliable answers to protect their privacy [3].

To address these concerns, researchers have traditionally relied upon snowball sampling, key informant sampling, and targeted sampling to investigate hidden populations. The shortcomings of each approach are detailed elsewhere, but the primary concern is derived from the lack of independence between observations, which is an unassailable artifact of snowball and targeted sampling [3]. Heckathorn's Respondent-Driven Sampling (RDS) offers an elegant addendum to chain referral procedures by limiting the number of potential recruits that each respondent can bring into a research program and incorporating both primary and secondary incentive structures into the recruitment process [3,25-27]. Respondents are rewarded for participating in the study (i.e. completing a survey or interview), but also receive rewards for referring others to the research program. This approach is successfully implemented in the study of intravenous drug users [3,28], AIDS patients [29], men who have sex with men [30], sex workers [31], and studies of jazz musicians [32].

When combined with controls to verify that a prospective respondent is a member of the targeted population, the collection of successive waves of respondents leads to "an equilibrium mix of recruits... that is independent of the characteristics of the subject or set of subjects from which recruitment began”, allowing for the calculation of unbiased population estimates [3,33-35]. RDS operates under four assumptions: 1) respondents accurately describe the size of their personal network within the sample population; 2) recruitment of additional respondents involves random selection by recruiters from their personal networks; 3) friendship ties are reciprocal; and 4) recruitment operates as a Markov process in that the transition probabilities of the last individual recruited converges towards an equilibrium (achieved when that individual's probability of selection is proportional to their personal network size) [27]. In the process of achieving equilibrium, key variables of interest (race, gender, or other theoretically specified statuses) are monitored throughout the recruitment process.

Previous studies relying on RDS required interviewers, a physical location to operate from, printed recruitment coupons, and a coupon tracking system; while the faceto-face interaction helps to explain why referral rates are so high in these studies, significant limitations arose when assembling samples. Researchers, regardless of their constitution and efficiency, can only interview so many people in one day, interview locations are not available at all times, and respondents' schedules do not always correspond with researchers'. Web-based RDS (webRDS) eliminates many of the logistical problems (though introducing new and complicated replacements), and tends to increase the speed of sample gathering [34,36,37].

Wejnert and Heckathorn's study of cross-racial friendship affiliations among college students demonstrates that large samples can be assembled in very short time periods (72 hours) if respondents view the study as important, the web interface is easy to use, and respondents' personal networks contain one or more individuals who possess the targeted attributes [34]. A primary drawback of webRDS, however, is that researchers are not able to meet with respondents face-to-face to confirm their status as attribute possessors (such as track marks for intravenous drug users) or to weed out respondents who provide fake responses in lieu of recruiting real people (to collect the recruitment reward) - though Bauermeister et al. telephoned each prospective recruit to verify their existence and to protect from virtual ballot stuffing [37]. To counteract the selection of fraudulent respondents, Wejnert and Heckathorn suggest keeping recruitment re- 
wards small and tracking internet protocol (IP) identification numbers so that multiple responses cannot emanate from the same computer [34].

Bauermeister et al. encountered both recruiting and tracking issues in their study of young adult drug use (the single webRDS examination of this potential population to date) [37]. 22 initial seeds were recruited via Facebook, took an online survey, and were asked to enter the email addresses of two friends - automated emails were sent to prospective recruits from the researchers [37]. Unfortunately, even with a $\$ 20$ incentive for completing the survey and $\$ 10$ incentives for each chain referral, only two additional respondents elected to participate in the second wave [37]. The researchers altered their protocol: first, a link to the survey was emailed to the original seeds with instructions to forward the message to their friends, to “(a) reduce threats to a potential young adult's confidentiality and privacy and (b) reduce concerns that referral chains were being broken as a result of filtering of... email invitations" [37]. There is no accounting of how successful this augmentation was, except that another alteration was required. This time, the authors "telephoned seeds and asked them about their experiences using the referral emails", finding that most seeds "had never forwarded the email and had not told their referrals that they had invited them to participate" [37]. Referral restrictions were loosened, allowing participants to recruit up to five respondents through a variety of social media (email, Facebook, text message, instant messenger). This alteration, while successful in rapidly increasing the sample size, led to recruiters forwarding the unique recruitment announcements to multiple individuals in hopes of capitalizing on the increased incentives. While their approach yielded an impressive, diverse sample in a short amount of time compared to traditional RDS procedures ( $n=3448$ in 2.5 months), it is questionable that accurate RDS network calculations were achieved due to the use of individual IDs by multiple respondents-in other words, it is not plausible that recruitment wave origination was traceable after recruitment forwarding restrictions were liberalized. The authors mention that "survey data were checked daily to screen out duplicate and fraudulent cases $(n=675)$ ), so it is possible that the RDS qualities of the network were preserved; however, this unknown without a presentation of the actual chain referral network [37]. Their study demonstrates the importance of proper controls to limit the use of unique IDs to one person; implementing such controls is relatively easy in a web-based survey environment.

Though unaddressed by Wejnert and Heckathorn due to the nature of their study, webRDS poses an additional complicating feature with hidden populations, particularly those who are security conscientious-that of pro- viding anonymous financial incentives [34]. Bauermeister et al. confront this by issuing "Visa e-gift" cards via email to respondents upon completion of their initial survey and reloading them after their chain referred recruits complete the survey [37]. This appears to be one of the more secure options available to researchers, but it does not fully protect participants in the case of compelled disclosure (i.e. subpoena), as the original "loading" of the cards is linked to researchers and recipients are required to provide a name and address before using the cards. Such a disclosure may seem like a minor consideration when studying use prevalence of multiple drugs in a large sample, but the issue is much more salient as sensitivity and security concerns become more of an issue-as is the case with drug producers or sellers. Limiting or completely eliminating monetary incentives to participants is one method of maintaining anonymity; however, no one has attempted a RDS study of this nature. This study, in addition to investigating marijuana users in Oregon, attempts the first non-monetary primary incentive RDS implementation.

\subsection{WebRDS Investigation of Marijuana Users in Oregon}

To answer the research questions posed in this study, I developed a webRDS protocol and web-based survey to examine a sample of marijuana users in Oregon. To investigate the role of different secondary incentive types in the success of RDS studies and to protect respondents' anonymity, I chose to forego all monetary payments. Instead, multiple non-monetary secondary incentives were implemented: 1 ) prospective respondents were appealed to based on the potential political and economic importance of examining their population; 2) live updates and total network referral counts for each respondent were posted on a web site to encourage competition among participants to recruit others; and 3) respondents were granted access to near-live aggregate data and summary statistics as the project developed.

Respondents were eligible to participate if they were Oregon residents, over the age of 18 , used marijuana in the last year, and received a unique study ID from a previous participant in the study. The web-based survey instrument included a question that tracked study IDs; any previously used IDs were barred from reuse. After completing the survey, respondents were redirected to another web page with instructions about the referral process, as well as links to five additional recruitment letters (in PDF format) that could be downloaded and shared with prospective recruits by email, Facebook, or instant message.

I identified a single "super seed" with a very large number of friends who are users, producers, and sellers 
of marijuana ( $n=44)$ in several counties identified in my parallel research study as "areas of interest" within Oregon (Benton, Josephine, and Multnomah). The super seed was fully briefed on the project, the referral process, and the importance of collecting chain referrals by following up with prospective respondents. The seed successfully recruited 26 respondents in the second wave from ten Oregon counties. However, the lack of monetary incentives and the format of the recruitment letters appear to have quickly affected recruitment rates compared to previous RDS studies (web-based and traditional), as the referral process died out with only 72 respondents (five waves). The implications of this finding are discussed later.

\subsection{Survey Instrument}

The survey instrument collected self-reported information on: 1) individual characteristics, such as gender, age, height, weight, frequency of exercise, county of residence, ethnicity, political party membership, education level, employment status, relationship status, occupational category, health insurance coverage, number of close friends, and income; 2) marijuana-related questions, including frequency of use, reasons for use, medical license status and roles, number of close friends who use, reasons for growing, number of plants growing, method of growing, source and reimbursement rate for obtained marijuana, amount consumed, and the perceived acceptance of marijuana use by immediate social circle and local community; and 3) a detailed political orientation index (using a replication of the 2011 Pew Political Research political typology questionnaire).

Variables of interest for hypothesis testing in this analysis include frequency of marijuana use, amount of marijuana used per month, number of close friends who use marijuana, perceived peer-group acceptance of marijuana use, use status (medical/non-medical), level of education, relationship status, number of children, and reasons for using marijuana. Frequency of marijuana use (ordinal) is operationalized as six options presented to respondents (less than once a month, once a month, 2 - 3 times a month, once a week, 2 - 3 times a week, and daily or near daily). Amount of marijuana used per month (ratio) is self-reported and measured in grams (0 - 100). The number of close friends who use marijuana is a ratio measure, with a minimum of zero and maximum of 20 . Perceived peer-group acceptance of marijuana use (ratio) is operationalized as the estimated percentage of friends, relatives, and coworkers who approve of marijuana use. Level of education (some high school, high school graduate (or GED), associate's degree, bachelor's degree, and master's degree or above) and relationship status (single, married or in a civil union, in a stable relationship (but not married or in a civil union)) are measured categori- cally. Presence of children in the home is a dichotomous, nominal variable (yes/no). Reasons for using (ordinal) include euphoria, sleep aid, pain management, appetite stimulant, relaxation, spiritual aspects, to be social, to dull reality, to forget problems or worries, stimulate creativity, depression, other medical reasons, to get "stoned", and other-any selected reasons are then rank-ordered.

\section{Results}

It appears that the lack of monetary incentives severely hampers the recruitment process, as the final sample consisted of 72 respondents and took approximately 2 months to gather from the initial referral. This finding is an important addition to the growing RDS literature on its own. The small sample size approached equilibrium, but did not achieve it - this impinges on the generalizability of the findings collected in this study. Even with these limitations, the results offer some insight into the population of Oregon marijuana users (though not statistically valid for generalizing to the population of marijuana users in Oregon or elsewhere).

The majority of responses were gathered in the first month of data collection. Figures 1-4 provide a visual representation of recruitment at key cross sections of the referral process. The most robust network growth occurred in the first two weeks after survey deployment, with over half of the total sample collected by the end of week one $(n=37)$ and nearly two-thirds assembled by week two $(n=49)$. The pattern of growth corresponds with diminishing response rates through the five waves of recruitment: 26 respondents are present in the second wave, 35 in the third wave, 9 in the fourth wave, and 2 in

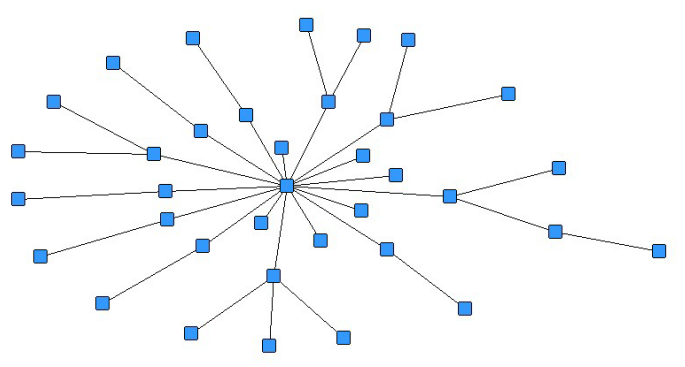

Figure 1. RDS sample at end of week 1.

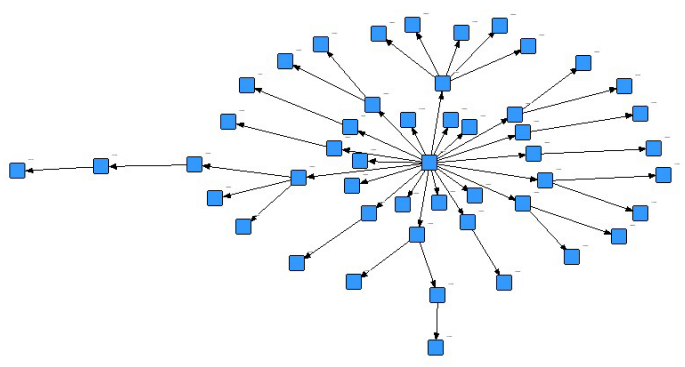

Figure 2. RDS sample at end of week 2. 


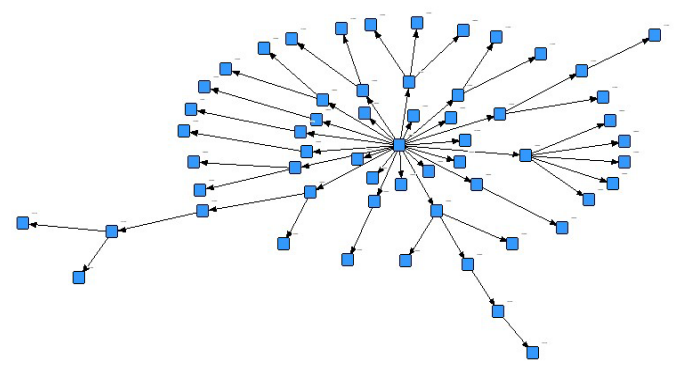

Figure 3. RDS sample at end of week 4.

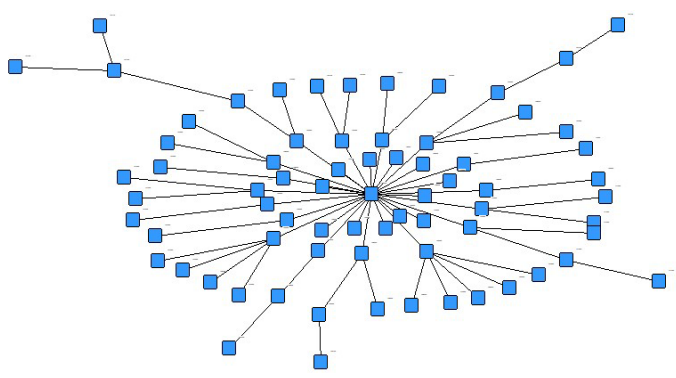

Figure 4. RDS sample at end of week 8.

the fifth wave. Though speculative, it appears as if recruitment was relatively successful through the third wave and that properly structured non-monetary incentives can work through this level of the referral process; however, the precipitous drop off in waves four and five indicate that any mechanisms at work in earlier waves lost their participation-inducing character. Those wishing to implement a non-monetary RDS recruitment process could likely attain equilibrium if enough initial seeds are selected and they are properly trained, but it is important to note that very few seeds are likely to enter the sample after the third wave.

The assembled sample (see Table 1 ) is predominantly male (63.9\%), white (90.3\%), well-educated (69.4\% with a bachelor's degree or above), in a stable relationship of some sort (77.6\%), are employed (89.8\%), illegally use marijuana (75\%), and are very frequent users of the drug (47.8\% daily or near daily use).

Despite an inability to generalize these findings to the marijuana-using population, most of this data corresponds with national surveys of drug use. A glaring difference is present in frequency of use figures. Estimates for Oregon indicate that $10.27 \%$ of individuals 26 or older have used marijuana in the last year, and 6.58\% used in the last month; for persons in the 18 - 25 age category, $36.96 \%$ used in the last year and $21.9 \%$ used in the last month [1]. For this sample (all used in the past year), past month usage is $78.5 \%$ for the 26 and older group $(n=14)$ and $87.5 \%$ in the 18 - 25 year old category $(n=48)$. Daily or near daily use accounts for $57.1 \%$ $(26+)$ and $43.7 \%(18-25)$ of respondents in these age groups.
Table 1. Description of RDS network sample.

\begin{tabular}{cccc}
\hline & Variable & $\%$ & $n$ \\
\hline Gender & Male & 63.9 & 46 \\
& Female & 36.1 & 26 \\
& & \\
Race & White & 90.3 & 65 \\
& Latino/a & 1.4 & 1 \\
& Asian American & 2.8 & 2 \\
Native American & 1.4 & 1 \\
Other & 1.4 & 1 \\
& & 2.8 & 2 \\
Education & & & \\
& Some high school & 0 & 0 \\
& High school grad & 19.4 & 14 \\
Associates degree & 11.1 & 8 \\
Bachelor's degree & 47.2 & 34 \\
& Master's or above & 22.2 & 16 \\
& & & \\
& & & \\
& & 14.5 & 10 \\
Use frequency & & 4.3 & 3 \\
& Less than once a month & 10.1 & 7 \\
& Once a month & 10.1 & 7 \\
& 2 - 3 times a month & 13.0 & 9 \\
Once a week & 47.8 & 33
\end{tabular}

Use status

Licensed medical user $\quad 25 \quad 18$ $\begin{array}{lll}\text { Illegal user } & 75 \quad 54\end{array}$

Relationship status

$\begin{array}{ccc}\text { Single or divorced } & 22.4 & 13 \\ \text { Married } & 39.7 & 23 \\ \text { Stable unmarried relationship } & 37.9 & 22\end{array}$

Employment status

Unemployed

$10.2 \quad 7$

Employed

$89.8 \quad 62$

Political party

$\begin{array}{ccc}\text { Republican } & 2.7 & 2 \\ \text { Democrat } & 44.4 & 32 \\ \text { Independent } & 18.0 & 13 \\ \text { Libertarian } & 1.4 & 1 \\ \text { Green } & 2.7 & 2 \\ \text { Other } & 2.7 & 2 \\ \text { Not registered } & 27.7 & 20\end{array}$

Exercise frequency

$\begin{array}{cc}1.5 & 1 \\ 8.9 & 6 \\ 7.4 & 5 \\ 11.9 & 8 \\ 25.3 & 17 \\ 31.3 & 21 \\ 10.4 & 7 \\ 2.9 & 2\end{array}$

BMI index

\begin{tabular}{ccc} 
Healthy & 61.1 & 44 \\
Overweight & 27.1 & 20 \\
Obese & 11.1 & 8 \\
\hline
\end{tabular}


Respondents are much fitter and exercise more often than average Americans, with 61.1\% reporting "healthy" body mass indexes and averaging four days of aerobic activity per week. However, this could be a sampling artifact brought on by overrepresentation of younger respondents (mean age: 31). The majority of respondents are registered as Democrats (44\%) or Independents (18\%), with a sprinkling of minor party representation as well; surprisingly, $27.7 \%$ are not registered with any political party. Political ideology measures suggest that marijuana users are relatively left-leaning overall, though conservative outliers are present (Figure 5).

Marijuana users' mean yearly incomes are higher than Oregon's average (\$32,962 vs. \$26,171), but, with a standard deviation of $\$ 27,424$, are also highly variable. Finally, the majority of respondents have never been arrested $(76.3 \%)$; of those who have ( $n=17)$, eight have been arrested for marijuana related charges.

Why do marijuana users - particularly those who use without a medical license-break the law and consume this drug? As Table 2 highlights, respondents' most widely cited reasons for using marijuana are to relax, stimulate creativity, alleviate pain, induce sleep, and to experience euphoria. Of the specific rationalizations offered in the survey, users also rank these five as their most important reasons for consuming marijuana (in order: sleep, relaxation, pain suppression, creativity stimulation, and euphoria). Differences emerged between licensed medical users $(n=18)$ and their illegal counterparts $(n=54)$ as well. Medical use is primarily engaged in to alleviate pain and induce sleep; illegal users seek relaxation and creativity stimulation, although medical users also report using the drug for relaxation. Very few associate their use with a desire to get "stoned", dull reality, or forget problems, and when they do, these rationalizations are ranked low in importance. The terms selected to describe use, in general, frame the drug as a positive contribution in users' lives.

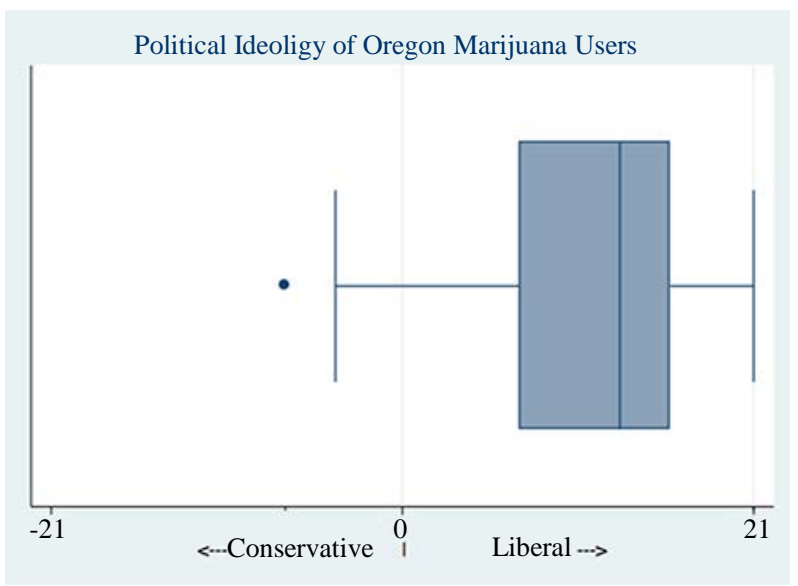

Figure 5. Political ideology of Oregon marijuana users.
Table 2. Counts and ranks of reasons for use.

\begin{tabular}{ccccc}
\hline \multirow{2}{*}{ Reason } & \multicolumn{4}{c}{$n$ ranked as \#1 } \\
\cline { 2 - 5 } & $n$ & Mean rank & Medical & Illegal \\
\hline Sleep & 23 & 1.97 & 4 & 2 \\
Relax & 43 & 2.34 & 1 & 14 \\
Other & 7 & 2.44 & 0 & 0 \\
Pain & 24 & 2.79 & 7 & 3 \\
Creativity & 28 & 3.25 & 0 & 5 \\
Other medical & 3 & 3.66 & 0 & 0 \\
Euphoria & 23 & 3.73 & 0 & 1 \\
Being social & 18 & 3.77 & 1 & 1 \\
Spirituality & 13 & 3.84 & 1 & 2 \\
Appetite & 11 & 4.36 & 0 & 0 \\
Dull reality & 6 & 4.50 & 0 & 0 \\
Forget problems & 9 & 4.66 & 0 & 1 \\
Get “stoned” & 13 & 4.84 & 0 & 2 \\
Depression & 7 & 5.85 & 0 & 0 \\
\hline
\end{tabular}

$n=71$.

The number of close friendships (mean: 10.86) reported by respondents in this sample is similar to those reported in previous studies of general populations (Roberts and Dunbar 2011) (see Table 3). This contradicts popular conceptions-though never investigated in a systematic way-of marijuana users as reclusive, anti-social, or otherwise socially maldeveloped. Figures 6 and 7 provide visualizations of the sample with their reported friendship ties included. Figure 7 highlights the high level of homophily present in the sample's friendship networks; $69 \%$ of close friends are also reported to be users of marijuana. The total sample size obviously hampers generalizability of this intriguing finding; this is especially true of the fourth and fifth waves of respondents. There is a possibility that an individual's frequency of use is a causal determinant of friendship composition, and that the abnormally large number of "every day" users present in this sample has skewed the average percentage of close friend users (though univariate regression suggests otherwise).

\subsection{Hypothesis Testing}

Due to the lack of RDS equilibrium in this sample, all hypothesis tests must be viewed as tentative and not fully supported by accurate population data—all findings and statements only apply to this particular sample of Oregon marijuana users. That said, the collected data suggests that individual marijuana use-both frequency and amount-is not related to either the number of friends who use $\left(\mathrm{H}_{1}\right)$ or peer-group acceptance of marijuana use $\left(\mathrm{H}_{2}\right)$. As illustrated previously (Table 1 ), marijuana users 
Table 3. Friend counts by recruitment wave and use.

\begin{tabular}{cccc}
\hline Wave & $n$ & $\begin{array}{c}\text { Close friends } \\
\text { (mean) }\end{array}$ & $\begin{array}{c}\text { Close friends who use } \\
\text { (mean \%) }\end{array}$ \\
\hline 2 & 27 & 12.5 & 68.3 \\
3 & 34 & 10.0 & 67.1 \\
4 & 6 & 10.1 & 72.8 \\
5 & 3 & 10.6 & 86.6 \\
\hline
\end{tabular}

$n=71$.

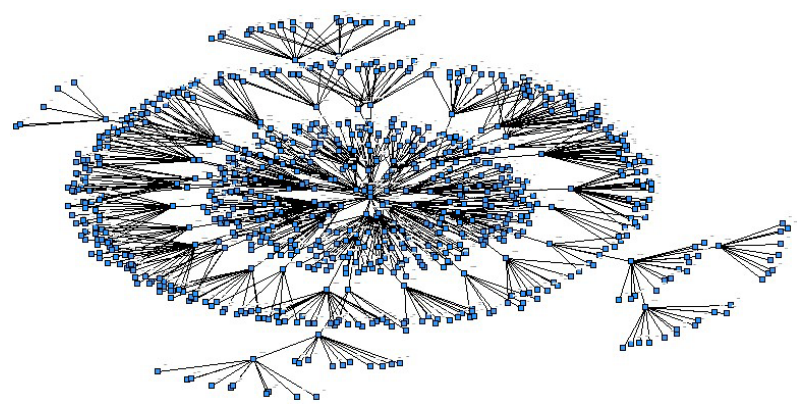

Figure 6. Sample with reported friendships imputed.

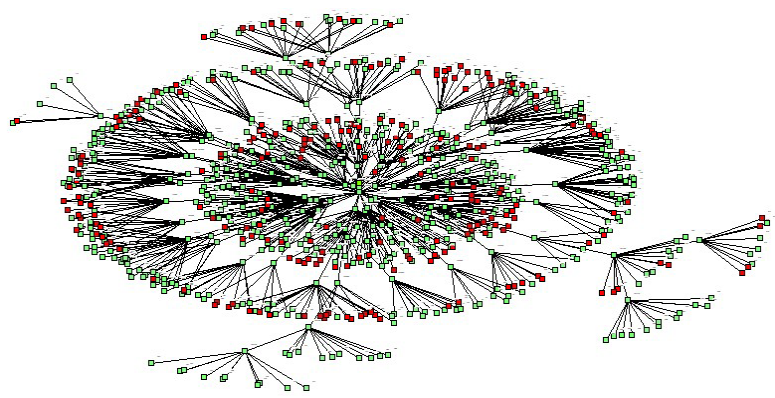

Figure 7. Sample with reported friendships imputed (users in green).

are friends with other marijuana users at a much higher rate than could be expected under a random distribution, and are, on average, significantly more educated than the general population $\left(\mathrm{H}_{3}\right)$. Are marijuana users more likely to be single than the general population $\left(\mathrm{H}_{4}\right)$ ? Nationally, $43 \%$ (96.6 million) of Americans over the age of 18 are "single" (unmarried) [38]. In this sample, 12 respondents were single, while 22 were married, and 22 were in a stable relationship. Compared to the national data, marijuana users appear less likely to be married; however, there were some missing responses to this particular question ( $n=16)$, and, overall, marijuana users are more likely to be in a stable relationship (78\% married or otherwise) than single (a distinction not made in US Census data). Missing data (valid $n=58$ ) is also an issue in determining if marijuana users are less likely to have children in the home than the general population average (33.5\%) $\left(\mathrm{H}_{5}\right)$. At $29 \%$, marijuana users appear to have slightly below slightly less likely to have children in the home than the general population. Medical users appear-as highlighted by the data present in Table 3-to use the drug to alleviate acute physical symptoms $\left(\mathrm{H}_{6}\right)$ with generalized pain indicated as the primary rational for using. Illegal users consume the drug to relax and stimulate creativity, but rank "numbing reality" ("getting stoned" and "dull reality") very low compared to other rationalizations $\left(\mathrm{H}_{7}\right)$.

\section{Discussion}

Despite not achieving RDS network equilibrium in this sample, the findings contribute in an important way to previous RDS studies and, in regards to marijuana users, warrant further investigation; the ramifications of daily or near daily use by a significant percentage of the marijuana using population are far reaching from multiple (health, criminal justice, economic, and cultural) perspectives. The basic demographic information collected on members of this particular drug using population suggest that marijuana users are not dramatically different from their non-using counterparts in many ways, but, in areas where they deviate from the norm, they tend to attain socially desirable attributes. Users are similar to average Americans in their number of close friends, employment status, arrest history ${ }^{1}$, and just slightly less likely to have children in the home; however, users' incomes are slightly higher than average, they exercise more regularly and maintain healthier overall weights, are more likely to have health insurance and be in a stable relationship, and are much more educated than the rest of the population. Users in this study are employed in diverse occupations: teachers $(16 \%)$, health care fields (23\%), managers $(11 \%)$, chefs or cooks $(11 \%)$ are the most cited categories, but the sample also includes lawyers, architects, artists, farmers, and construction workers. While incomes are higher than average, they are lower than would be predicted for such high educational attainment.

The distinctly liberal political ideology of users raises questions. Without broaching the subject of causality (i.e. does marijuana use make you liberal or does being liberal make you use marijuana?), does the character of a drug lend itself to a particular ideology or worldview? While this question is not answerable with the collected data, the strength of the findings suggests further research.

The high frequency of use reported could be an artifact of sampling bias, with frequent users recruited by previous participants more often or simply more willing to

\footnotetext{
${ }^{1}$ One troubling aspect of this study's results is that the eight respondents arrested on marijuana related charges are well educated (four hold a bachelor's degree, four hold a master's degree or above); commenting without knowing the details of each situation would be inappropriate, but - on the face-such a circumstance raises the oft-cited specter of marijuana illegality causing more harm than good [39].
} 
participate in a non-monetarily incentivized study. On the other hand, the paucity of investigations of this particular population makes such a conclusion difficult to justify, particularly as the drug becomes more acceptable to society at large-more detailed data seems necessary. If the average user ingests the drug regularly (multiple times per week) and does so using traditional means (i.e. smoking), public health mitigation strategies could direct users to less damaging alternatives (i.e. vaporization) that would reduce economic losses due to respiratory ailments. Similarly, high frequencies of use would suggest that additional investigations of marijuana-induced driving impairment are required, as well as appropriate methods of assessing impairment levels.

The composition of users' friendship networks also raises important considerations, particularly as the drug moves into the realm of quasi-legality in several states and others attempt to identify successful electoral strategies to achieve similar results. If marijuana users' in-network friendship selection is as strong as suggested by this study (67\%), the likelihood of a non-user being friends with a user should be small. The effect of limited close friend relationships between non-users and users could have significant implications for the non-using population's perceptions of the drug and its acceptability in social contexts, since individuals may have a difficult time accepting that marijuana users come in all shapes, sizes, and abilities when they are close friends with only one or two. Additionally, this finding provides another confirmation of the homophilic tendencies of status groups and suggests that marijuana users represent a distinct sub-population of our society [40].

While initial use and initiation into the methods of use (knowing how to obtain and ingest the drug) are accurately described by social learning and differential association theories, prolonged use extending into and through adulthood-especially when conducted in nonsocial situations - is not adequately explained. The data collected in this study suggests that adult marijuana use is best viewed through Akers' social learning theory, particularly the more nuanced version that attributes continued use of drugs to the biopsychological effects produced their consumption [12]. For Hirschi's social control theory to provide a valid explanation of continued adult marijuana use, users must lack a combination of social bonds that non-users possess [14]. If anything, that data suggests that this study's respondents are social bond exemplars in many regards. While this study does not offer a rigorous test of these theories (due to a lack of statistical significance) and cannot fully reject their applicability to adult marijuana use, the face validity of both social control and differential association theories is questionable. To this point, no theory of deviance or social control has examined the causal forces at work be- fore and after a punctuation in the social norm equilibrium-marijuana legalization (in various forms) offers us an immediate and tangible opportunity to explore this phenomenon.

\section{Conclusions}

This study contributes to the emerging RDS methodology literature by demonstrating that non-monetary primary incentives are not effective recruiting tools, especially after the third wave of recruitment. WebRDS sampling procedures are viable as a methodological strategy to investigate this particular hidden population, but monetary inducements appear necessary to achieve appropriate sample sizes. The results suggest that non-monetary primary incentives may work, but studies using them should include large initial seed pools and adequate seed training.

The study also suggests that Oregon marijuana users are not significantly different from the general population in many substantial ways, though their deviations-outside of marijuana use-are in socially acceptable and rewarding ways. Additionally, Oregon marijuana users are liberal in political orientation, associated with other marijuana users at higher rates than those could be expected from random chance, and they use the drug far more often than previous research projected. The findings presented in this study demonstrate the necessity for further research on marijuana users, particularly as the drug moves into mainstream acceptance (with legalization of recreational use in Washington and Colorado). If a "before-and-after" study of friendship networks was conducted in a state where the drug becomes legal, we could gain significant insight into the causal effect of laws on the formation of status groups in a particular society.

\section{REFERENCES}

[1] SAMSHA, "National Survey on Drug Use and Health,” US Department of Health and Human Services, Substance Abuse and Mental Health Services Administration, 2009. http://oas.samhsa.gov/NSDUH/2k9NSDUH/2k9ResultsP. pdf

[2] J. Gettman, "Marijuana Production in the United States," The Bulletin of Cannabis Reform, No. 2, 2006.

[3] D. Heckathorn, "Respondent-Driven Sampling: A New Approach to the Study of Hidden Populations," Social Problems, Vol. 44, No. 2, 1997, pp. 174-199. http://dx.doi.org/10.2307/3096941

[4] D. M. DeNitto and N. G. Chol, "Marijuana Use Among Older Adults in the USA: User Characteristics, Patterns of Use, and Implications for Intervention,” International Psychogeriatrics, Vol. 23, No. 5, 2011, pp. 732-741. http://dx.doi.org/10.1017/S1041610210002176

[5] H. S. Becker, "Becoming a Marihuana User," American 
Journal of Sociology, Vol. 59, No. 2, 1953, pp. 235-242. http://dx.doi.org/10.1086/221326

[6] H. S. Becker, "Outsiders: Studies in the Sociology of Deviance,” Free Press, New York, 1963.

[7] E. Sutherland and D. Cressey, "Criminology," 9th Edition, Lippincott, Philadelphia, 1974.

[8] C. Tittle, M. Burke and E. Jackson, "Modeling Sutherland's Theory of Differential Association: Toward an Empirical Clarification,” Social Forces, Vol. 65, No. 2, 1986, pp. 406-432.

[9] R. L. Burgess and R. L. Akers, "A Differential Association-Reinforcement Theory of Criminal Behavior," Social Problems, Vol. 14, No. 2, 1966, pp. 128-147. http://dx.doi.org/10.2307/798612

[10] R. Akers, R. Burgess, and W. Johnson, "Opiate Use, Addiction, and Relapse,” Social Problems, Vol. 15, No. 4, 1968, pp. 459-469. http://dx.doi.org/10.2307/799834

[11] R. Akers, "Deviant Behavior: A Social Learning Approach,” Wadsworth, New York, 1973.

[12] R. Akers, M. Krohn, L. Lanza-Kaduce and M. Radosevich, "Social Learning and Deviant Behavior: A Specific Test of A General Theory," American Sociological Review, Vol. 44, No. 4, 1979, pp. 636-655. http://dx.doi.org/10.2307/2094592

[13] E. Goode, “Marijuana Smokers,” Basic Books, New York, 1970.

[14] T. Hirchi, "Causes of Delinquency," University of California Press, Berkeley, 1969.

[15] R. Sampson and J. Laub, "Understanding Variability in Lives through Time: Contributions of Life-Course Criminology," Studies on Crime and Crime Prevention, Vol. 4, No. 2, 1995, pp. 143-158.

[16] J. Derzon and M. Lipsey, "What Good Predictors of Marijuana Use Are Good for,” School Psychology International, Vol. 20, No. 1, 1999, pp. 69-85. http://dx.doi.org/10.1177/0143034399201006

[17] D. Kandel, "Homophily, Selection and Socialization in Adolescent Friendships," American Journal of Sociology, Vol. 84, No. 2, 1978, pp. 427-436. http://dx.doi.org/10.1086/226792

[18] A. Mauss, "Anticipatory Socialization toward College as a Factor in Adolescent Marijuana Use," Social Problems, Vol. 16, No. 3, 1969, pp. 357-364. http://dx.doi.org/10.2307/799669

[19] J. Brown, "Turning Off: Cessation of Marijuana Use after College,” Social Problems, Vol. 21, No. 4, 1974, pp. 527538. http://dx.doi.org/10.2307/799990

[20] K. Yamaguchi and D. Kandel, "On the Resolution of Role Incompatibility: A Life Event History Analysis of Family Roles and Marijuana Use," American Journal of Sociology, Vol. 90, No. 6, 1985, pp. 1284-1325. http://dx.doi.org/10.1086/228211

[21] C. Reinarman, H. Nunberg, F. Lanthier and T. Heddleston, "Who Are Medical Marijuana Patients? Population Characteristics from Nine California Assessment Clinics," Journal of Psychoactive Drugs, Vol. 43, No. 2, 2011, pp. 128-135. http://dx.doi.org/10.1080/02791072.2011.587700

[22] A. Weil, N. Zinberg and J. Nelson, "The Effects of Marijuana,” Science, Vol. 162, No. 3859, 1968, pp. 1234-1242. http://dx.doi.org/10.1126/science.162.3859.1234

[23] B. Zablocki, A. Aidala, S. Hansell and H. R. White, "Marijuana Use, Introspectiveness, and Mental Health,” Journal of Health and Social Behavior, Vol. 32, No. 1, 1991, pp. 65-79. http://dx.doi.org/10.2307/2136800

[24] K. Hillig and P. Mahlberg, "A Chemotaxonomic Analysis of Cannabinoid Variation in Cannabis (Cannabaceae)," American Journal of Botany, Vol. 91, No. 6, 2004, pp. 966-975. http://dx.doi.org/10.3732/ajb.91.6.966

[25] D. Heckathorn, "Respondent-Driven Sampling II: Deriving Valid Population Estimates from Chain-Referral Samples of Hidden Populations,” Social Problems, Vol. 49, No. 1, 2002, pp. 11-34.

http://dx.doi.org/10.1525/sp.2002.49.1.11

[26] D. Heckathorn, "Extensions of Respondent-Driven Sampling: Analyzing Continuous Variables and Controlling for Differential Recruitment,” Sociological Methodology, Vol. 37, No. 1, 2007, pp. 151-207. http://dx.doi.org/10.1111/j.1467-9531.2007.00188.x

[27] E. Volz and D. Heckathorn. "Probability Based Estimation Theory for Respondent-Driven Sampling," Journal of Official Statistics, Vol. 24, No. 1, 2008, pp. 79-97.

[28] D. Heckathorn, S. Semaan, R. Broadhead and J. Hughes, "Extensions of Respondent-Driven Sampling: A New Approach to the Study of Injection Drug Users Aged 18 - 25," AIDS and Behavior, Vol. 6, No. 1, 2002, pp. 55-67. http://dx.doi.org/10.1023/A:1014528612685

[29] D. Heckathorn, R. Broadhead, D. Anthony and D. Weakliem, "AIDS and Social Networks: HIV Prevention through Network Mobilization,” Sociological Focus, Vol. 32, No. 2, 1999, pp. 159-179. http://dx.doi.org/10.1080/00380237.1999.10571133

[30] J. Ramirez-Valles, D. Heckathorn, R. Vazques, R. Diaz and R. Campbell, "From Networks to Populations: The Development and Application of Respondent-Driven Sampling among IDUs and Latino Gay Men,” AIDS and Behavior, Vol. 9, No. 4, 2005, pp. 387-402. http://dx.doi.org/10.1007/s10461-005-9012-3

[31] L. Johnston, M. Malekinejad, C. Kendall, I. Iuppa and G. Rutherford, "Implementation Challenges to Using Respondent-Driven Sampling Methodology for HIV Biological and Behavioral Surveillance: Field Experiences in International Settings,” AIDS and Behavior, Vol. 12, No. 1, 2008, pp. S231-S141. http://dx.doi.org/10.1007/s10461-008-9413-1

[32] D. Heckathorn and J. Jeffri, "Finding the Beat: Using Respondent-Driven Sampling to Study Jazz Musicians,” Poetics, Vol. 28, No. 4, 2001, pp. 307-329. http://dx.doi.org/10.1016/S0304-422X(01)80006-1

[33] M. Salganik and D. Heckathorn, "Sampling and Estimation in Hidden Populations Using Respondent-Driven Sampling," Sociological Methodology, Vol. 34, No. 1, 2004, pp. 193-239. http://dx.doi.org/10.1111/j.0081-1750.2004.00152.x

[34] C. Wejnert and D. Heckathorn, "Web-Based Network Sampling: Efficiency and Efficacy of Respondent-Driven 
Sampling for Online Research," Sociological Methods and Research, Vol. 37, No. 1, 2008, pp. 105-134. http://dx.doi.org/10.1177/0049124108318333

[35] C. Wejnert, “An Empirical Test of Respondent-Driven Sampling: Point Estimates, Variance, Degree Measures, and Out-of-Equilibrium Data,” Sociological Methodology, Vol. 39, No. 1, 2009, pp. 73-116. http://dx.doi.org/10.1111/j.1467-9531.2009.01216.x

[36] L. Bengtsson, X. Lu, Q. C. Nguyen, M. Camitz, N. Le Hoang, F. Liljeros and A. Thorson. "Implementation of Web-Based Respondent-Driven Sampling among Men Who Have Sex with Men in Vietnam,” PLoS ONE, Vol. 7, No. 11, 2012, p. e49417. http://dx.doi.org/10.1371/journal.pone.0049417

[37] J. Bauermeister, M. Zimmerman, M. Johns, P. Glowacki, S. Stoddard and E. Volz, "Innovative Recruitment Using
Online Networks: Lessons Learned From an Online Study of Alcohol and Other Drug Use Utilizing a Web-Based, Respondent Driven Sampling (webRDS) Strategy,” Journal of Studies on Alcohol and Drugs, Vol. 73, No. 5, 2012, pp. 834-838.

[38] US Census Bureau, 2010. http://www.census.gov/newsroom/releases/archives/facts for_features_special_editions/cb10-ff18.html

[39] D. Nutt, L. King and L. Phillips, "Drug Harms in the UK: A Multicriteria Decision Analysis,” The Lancet, Vol. 376, No. 9752, 2010, pp. 1558-1565. http://dx.doi.org/10.1016/S0140-6736(10)61462-6

[40] M. McPherson, L. Smith-Lovin and J. Cook, "Birds of a Feather: Homophily in Social Networks," Annual Review of Sociology, Vol. 27, No. 1, 2001, pp. 415-444. http://dx.doi.org/10.1146/annurev.soc.27.1.415 